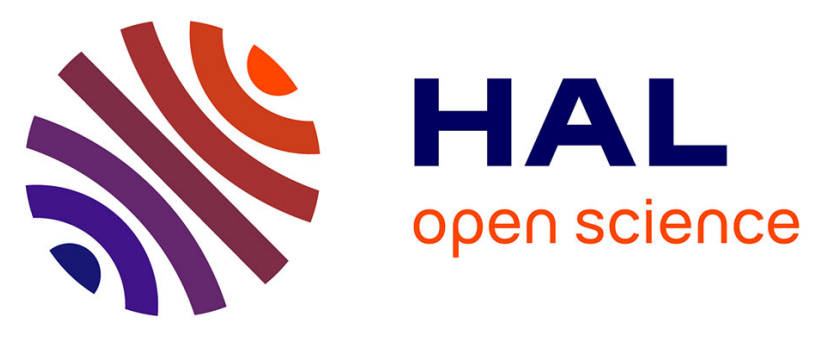

\title{
Robust Multi-Parameter Sensing Probe for Water Monitoring Based on ALD-Coated Metallic Micro-patterns and Carbon Nanotube Printing
}

Massimo Pellegrino, William Cesar, Frédéric Marty, Martine Capo Chichi, Bérengère Lebental, Tarik Bourouina

\section{To cite this version:}

Massimo Pellegrino, William Cesar, Frédéric Marty, Martine Capo Chichi, Bérengère Lebental, et al.. Robust Multi-Parameter Sensing Probe for Water Monitoring Based on ALD-Coated Metallic Micropatterns and Carbon Nanotube Printing. IEEE NEMS 2016 - The 11th Annual IEEE International Conference on Nano/Micro Engineered and Molecular Systems, Apr 2016, Matsushima Bay, Japan. 2p, 10.1109/NEMS.2016.7758263 . hal-01395020

\section{HAL Id: hal-01395020 https://hal.science/hal-01395020}

Submitted on 10 Nov 2016

HAL is a multi-disciplinary open access archive for the deposit and dissemination of scientific research documents, whether they are published or not. The documents may come from teaching and research institutions in France or abroad, or from public or private research centers.
L'archive ouverte pluridisciplinaire HAL, est destinée au dépôt et à la diffusion de documents scientifiques de niveau recherche, publiés ou non, émanant des établissements d'enseignement et de recherche français ou étrangers, des laboratoires publics ou privés. 


\title{
Robust Multi-Parameter Sensing Probe for Water Monitoring Based on ALD-Coated Metallic Micro-patterns and Carbon Nanotube Printing
}

\author{
Massimo Pellegrino, William Cesar, Frederic Marty, Martine Capo-Chichi, \\ Bérengère Lebental and Tarik Bourouina, Senior Member, IEEE
}

\begin{abstract}
We report on a multi-sensing probe for water network monitoring enabling simultaneous measurement of water electrical conductivity, flow-rate, temperature and $\mathrm{pH}$. A very simple fabrication process is used where all physical sensors are obtained only from micro-patterning of glass, combining platinum, gold. Further coating using Atomic Layer Deposition (ALD) is achieved for the purpose of reducing both electroerosion and biofouling, while keeping the sensor's electrical and thermal functionalities. This is critical for long-term reliability of sensors immersed in water. Carbon nanotubes are then inkjetprinted last for the $\mathrm{pH}$ sensor. Lateral size of each sensing elements does not exceed a few $100 \mu \mathrm{m}$. This small footprint allowed implementing a redundancy strategy on the chip, not only for reliability purposes but also to accommodate for different measurement ranges based on scalable designs.
\end{abstract}

\section{BACKGROUND}

Motivated by the needs for large scale deployment of low-cost sensors for monitoring water networks, we developed a multisensor chip based on a simple fabrication process involving only metal and CNT micro-patterning on glass. This enables cointegration of metallic-based flow-rate sensors, temperature sensors and electrical conductivity sensors as well as CNT-based $\mathrm{pH}$ sensors. All those sensors rely on combination of resistors and electrical pads as the only elementary building blocks.

\section{Current Results}

The flow-rate measurement is achieved thanks to a conventional hot-wire anemometric element [1] involving one resistive heating element and two thermistors. Accurate temperature measurement is obtained thanks to a four-port resistive device. Water conductivity sensor consists of a fourprobe arrangement involving two external electrodes for current injection at constant amplitude and two internal electrodes for voltage readout. In this latter case, the current is flowing inside the water environment and involves electrochemical phenomena, which imposes operating in AC mode at appropriate frequency. The $\mathrm{pH}$ sensor consists of a printed multi-walled carbon nanotube network lying between contact gold electrodes in a two-port resistive configuration. Glass was chosen as the substrate material for the full system for its superior electrical and thermal insulation properties compared to silicon.

This work has received funding from the European Union's H2020 Programme for research, technological development and demonstration under grant agreement No 644852 .

M. Pellegrino, W. Cesar, F. Marty and M. Capo-Chchi and T. Bourouina (e-mail: t.bourouina@esiee.fr) are with Université Paris-Est, ESYCOM-Lab, ESIEE, Noisy-le-Grand, France.

B. Lebental is with IFSTTAR, COSYS/LISIS, Université Paris-Est, Marnela-Vallée, France and with LPICM, CNRS, Ecole Polytechnique, Université Paris Saclay, Palaiseau, France.
Each of the elementary sensors occupies typically $500 \mu \mathrm{m} x$ $500 \mu \mathrm{m}$. Such small footprint enabled implementing different designs for electrical conductivity and flow-rate sensors on the same chip, so as to fit with different measurements ranges. This enables addressing multiple applications including waste water, rain water and drinking water. The small footprint also allowed duplication of exactly similar sensors for redundancy. The reliability was further addressed in the fabrication process through adding a protective layer formed by ALD, whose advantage is not only the conformal deposition which ensures complete protection against water but also the thinness $(10 \mathrm{~nm}$ here) to ensure than both electrical and thermal contacts are not affected in $\mathrm{AC}$ mode. Both $\mathrm{Al}_{2} \mathrm{O}_{3}$ and $\mathrm{TiO}_{2}$ are considered for ALD as those materials are also known as good candidates regarding their anti-fouling properties [2].

Figure 1 shows photos of the fabricated multi-sensor glass chip on the top of a one-cent coin and the chip assembled to a PCB probe. The electrical wire bonds are then hermetically protected against water using UV-cured epoxy. Due to the specific constraints inherent to operation in aqueous environment, measurement of electrical conductivity is the most critical. It requires careful sensor design and operation conditions. Typical measured responses are shown in Figure 3; while operation at a frequency of $500 \mathrm{~Hz}$ led to strong non-linearity, the measured response at $5 \mathrm{kHz}$ revealed excellent linear response, better than $0.5 \%$ over the full range extending from $200 \mu \mathrm{S} / \mathrm{cm}$ to $2200 \mu \mathrm{S} / \mathrm{cm}$.

Accelerated aging was performed by operating the conductivity sensor at a voltage level 1000x higher than the normal operation, in order to stimulate effective electro-erosion of the metallic electrodes and in the same time to evaluate the effectiveness of the ALD coating. The result of this experiment is illustrated in Figure 4. It reveals that, while the square unprotected electrodes have been deteriorated, other electrode patterns remained unaffected. This promising preliminary result is now being complemented by further experiments.

We are currently working towards the further co-integration of additional chemical sensors based on printed carbon nanotubes functionalized for specific sensitivity to chemical pollutants. The resulting system will integrate 7 different types of sensors and a total of 15 sensing elements.

\section{REFERENCES}

[1] J. Van Kuijk, T.S.J. Lammerink, H.E. de Bree, M. Elwenspoek, J.H.J, Fluitman, Sensors and Actuators A, 46-47 (1995) 369-372.

[2] T. Kallio, S. Alajoki, V. Pore, M. Ritala, J. Laine, M. Leskelä, P. Stenius, Colloids and Surfaces A: Physicochem. Eng. Aspects, 291 (2006), 162-176. 

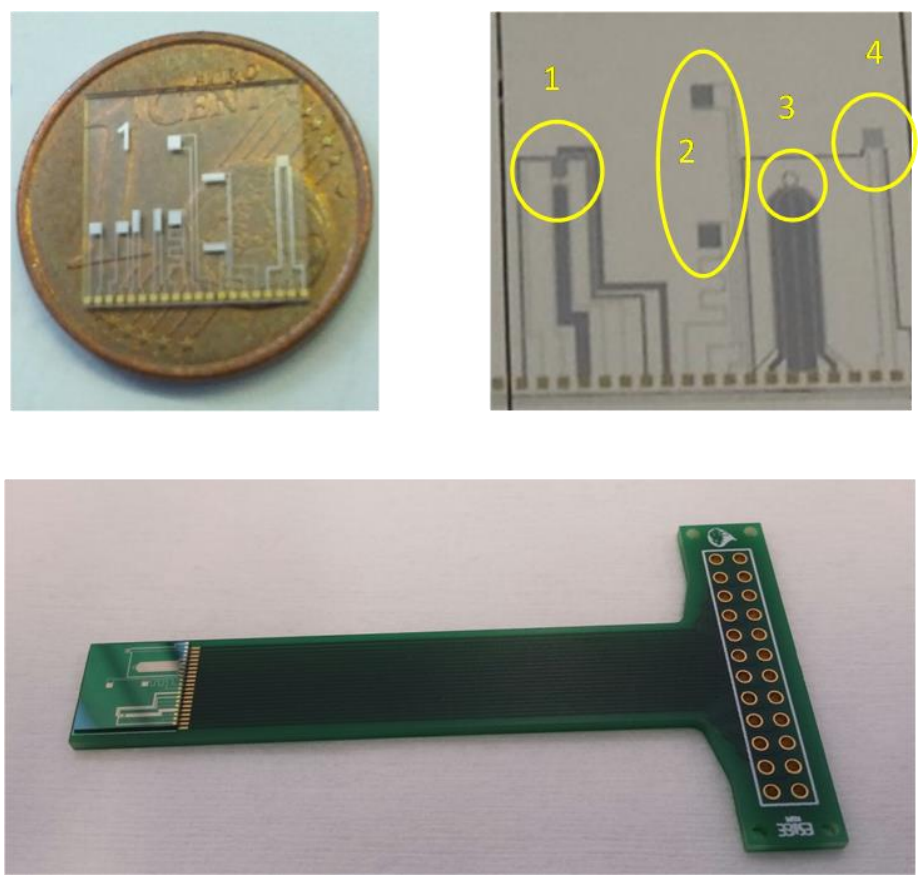

Figure 1: Fabricated multi-sensing water probe. (a) Upper left: the multi-sensor chip obtained from double-metal patterning of glass ; (b) Upper right : details on a typical chip containing two flow-rate sensors (\#1 and \#3), one conductivity sensor (\#2) and one temperature sensor (\#4); Lower photo : Chip on a PCB probe.

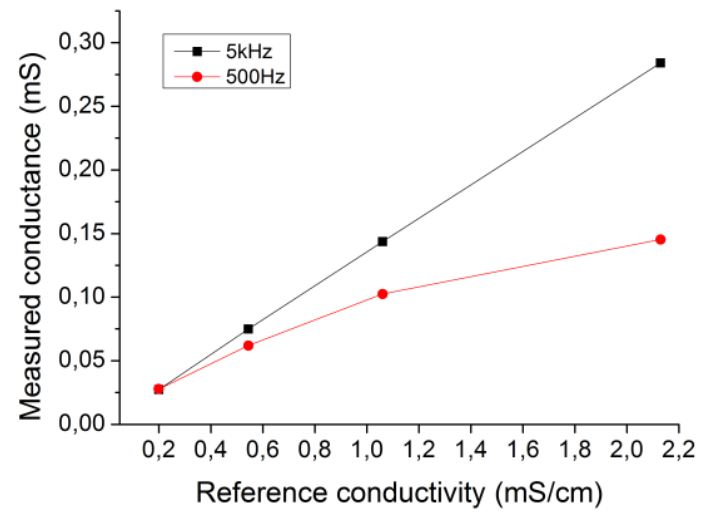

Figure 3: Measured response of the conductivity sensor recorded at different operating frequencies. While the red curve recorded at 500 $\mathrm{Hz}$ reveal non-linear response (as expected from simulation), the black curve recorded at $5 \mathrm{kHz}$ revealed excellent linearity (also as expected from simulation) which is here better than $0.5 \%$ over the measurement range extending from 0.2 to $2.2 \mathrm{mS} / \mathrm{cm}$.

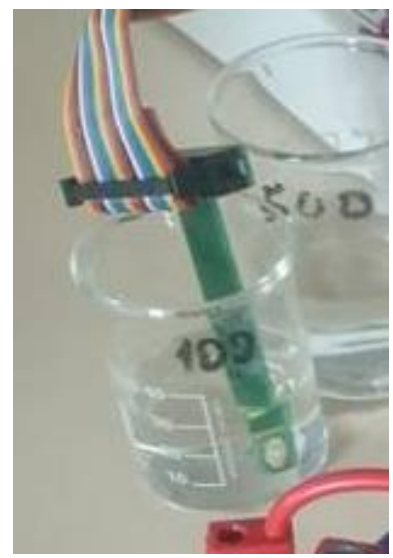

Figure 2: Part of the measurement setup involving immersion of the probe in different samples of calibrated conductivity standards.

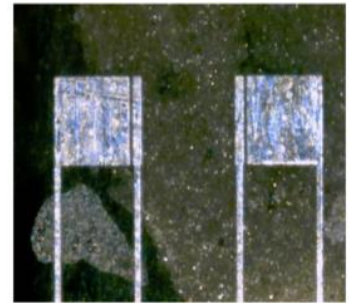

(a)

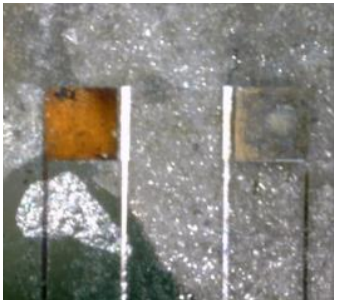

(b)
Figure 4: Photos before (a) and after (b) an accelerated aging experiment (operation at 1 Volt instead of $1 \mathrm{mV}$ ) reveals that the electrochemicallyinduced corrosion is concentrated in the regions of the two (brown) squares which are not protected by the

(a)
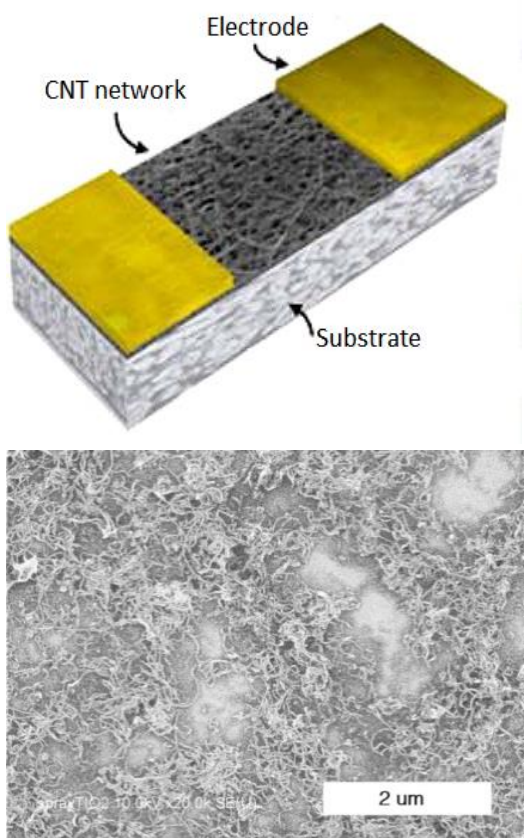

Figure 5: (a) schematic of the resistive CNTbased $\mathrm{pH}$ sensor; (b) printed MWCNT network 